\title{
Constituição do discurso da autonomia de idosas no cotidiano de uma Instituição de Longa Permanência para Idosos
}

\author{
Constitution of autonomy discourse of older person in the daily life of a Long- Term Care Facility \\ for the older person
}

Isadora Queiroz Correa Garchet Furtado' (DD Isabela Silva Câncio Velloso' $\mathbb{D}$ Carolina Sales Galdino? $\mathbb{D}$

\section{Resumo}

Objetivo: analisar a constituição do discurso da autonomia da pessoa idosa em uma Instituição de Longa Permanência, na perspectiva de profissionais e de idosas institucionalizadas. Método: pesquisa qualitativa, desenvolvida na perspectiva do referencial pós-estruturalista, realizada em uma instituição filantrópica da cidade de Belo Horizonte, Minas Gerais, Brasil. Os dados foram coletados no período de janeiro a março de 2018, por meio de entrevista semiestruturada, com 13 profissionais e sete idosas, análise documental e observação e foram submetidos à análise de discurso.Resultados: os efeitos da institucionalização na constituição da autonomia das idosas pode ser observado nos discursos das idosas e dos profissionais. A Instituição se constitui num local de disciplina, com rotinas bem estabelecidas, com pouco espaço para a tomada de decisão das idosas. Sua autonomia fica esquecida, pois as rotinas, de certa forma, encobrem seus desejos, suas escolhas e sua própria liberdade. Conclusão: para um funcionamento adequado da estrutura, limites e regras fazem-se necessários. Entretanto, é importante considerar que as normas não são utilizadas, unicamente, como instrumento de controle e cerceamento do exercício de tomada de decisão das idosas. A transição epidemiológica exige das instituições mudanças em suas práticas cotidianas, advindas de políticas públicas específicas para as instituições, com a definição clara de seu papel e diretrizes para uma prática qualificada.

\section{Abstract}

Objective: to analyze the constitution of autonomy discourse of the older personin a Long-Term Institution, from the perspective of professionals and institutionalized older person women. Method: qualitative research, developed from the perspective of the post-structuralist framework, fulfilled in a philanthropicinstitution in the city of Belo Horizonte, Minas Gerais, Brazil. Data were collected, from January to March 2018,

Palavras-chave: Idoso. Instituição de Longa Permanência para Idosos. Autonomia Pessoal. Institucionalização. Envelhecimento.

Keywords: Elderly. Home for the Aged. Personal autonomy. Institutionalization. Aging.

Universidade Federal de Minas Gerais, Departamento de Enfermagem Aplicada, Programa de Pósgraduação em Enfermagem. Belo Horizonte, MG, Brasil.

Os autores declaram não haver conflito na concepção deste trabalho.

Não houve financiamento para a execução deste trabalho.

Correspondência/Correspondence 
through semi-structured interviews with 13 professionalsand seven older person women, document analysis and observation and were submitted to discourse analysis. Results: the effects of institutionalization on theconstitution of the older person's autonomy can be observed in the speeches of the older person and professionals. The Institution is a place of discipline, with well-established routines, with little space for older person women to make decisions. Their autonomy is forgotten, because routines, in a way, cover up their desires, their choices and their own freedom. Conclusion: for a proper functioningof the structure, limits and rules are necessary. However, it is important to consider that the standards are not used solely as an instrument for controlling and restricting the older person women's decision-making exercise. The epidemiological transition requires from institutions changes in their daily practices, arising from specific public policies for institutions, with a clear definition of their role and guidelines for a qualified practice.

\section{INTRODUÇÃO}

As políticas públicas de saúde brasileiras privilegiam a permanência e o cuidado da pessoa idosa no domicílio, como forma de promover a saúde, prevenir incapacidades e manter a capacidade funcional do idoso dependente 1 . No entanto, com as mudanças na sociedade e na estrutura familiar, esse cuidado, antes restrito ao núcleo familiar, particularmente, às mulheres, assumiu um perfil diferente, diante das exigências do mercado e da ampliação da participação das mulheres no mercado de trabalho².

Nesse contexto, a institucionalização da pessoa idosa passa a ser uma alternativa a se considerar, com um consequente aumento da demanda por vagas em Instituições de Longa Permanência para Idosos (ILPIs).

Historicamente, esses locais são reconhecidos como lugares de isolamento, segregação social e geracional, nos quais os indivíduos são desprovidos de liberdade ${ }^{3}$. Instituições dessa natureza compõem o rol das instituições totais, ou seja, instituições que servem de residência para um certo número de indivíduos em situação semelhante, por um considerável período de tempo, durante o qual os mesmos são separados da sociedade em geral e levam uma vida fechada ${ }^{4}$. As instituições totais se constituem em ambientes opressivos, onde os reclusos têm seu cotidiano amplamente controlado, com enfraquecimento de sua autonomia ${ }^{5}$.
A autonomia, um componente central do bemestar geral do idoso, está fortemente ancorada no atendimento das necessidades básicas de um indivíduo, com influência sobre sua dignidade, integridade, liberdade e independência ${ }^{6}$. Mesmo diante de uma diversidade de questões conceituais, em geral, as teorias acerca da autonomia convergem em duas condições essenciais: liberdade, que se refere à independência de influências controladoras, e agência, que é a capacidade de agir intencionalmente?

A autonomia remete à questão da relação do sujeito com o outro e se constitui na tensão da sociedade instituída com a sociedade instituinte, de modo que a ideia de autonomia só pode ser concebida na análise do processo histórico e social ${ }^{8}$. Nesse sentido, o contexto do envelhecimento da população deve nos conduzir a reflexões acerca desse processo, o que abrange questões relacionadas à autonomia no âmbito da institucionalização da pessoa idosa, pois estima-se que $1 \%$ dos brasileiros com mais de 60 anos residam em ILPIs?.

O idoso pode ter sua autonomia cerceada com a institucionalização, uma vez que as rotinas impostas nesse cenário são fatores que podem estar associados à possibilidade de redução do exercício de sua própria vontade? Isso justifica a relevância de se investigar, sob diferentes óticas, a constituição do discurso da autonomia de idosos institucionalizados. Assim, o presente artigo teve como objetivo analisar a constituição do discurso da autonomia da pessoa idosa em uma Instituição de 
Longa Permanência, na perspectiva de profissionais e de idosas institucionalizadas.

\section{MÉTODO}

O presente estudo é uma pesquisa qualitativa, que tem o pós- estruturalismo como referencial teórico-filosófico. A pesquisa qualitativa aprofundase na intensidade, na singularidade e no significado das coisas, em um ciclo que não se fecha, pois, toda pesquisa produz conhecimento e gera novas indagações ${ }^{10}$. Esses questionamentos se interligam com a perspectiva do pós-estruturalismo, uma vez que seu fundamento é questionar a própria realidade, quem são os indivíduos que a constituem e quais as relações sociais estabelecidas em um determinado cenário ${ }^{11}$. Além disso, o pós-estruturalismo permite uma reflexão acerca dos conceitos utilizados pela sociedade, os quais não são admitidos como verdades universais, mas sim como resultado de mudanças nas relações de poder ${ }^{12}$.

A pesquisa foi realizada em uma ILPI filantrópica da cidade de Belo Horizonte, Minas Gerais (MG), Brasil, onde residem exclusivamente mulheres. Foram realizadas duas visitas prévias na instituição para que a mesma fosse selecionada como campo de pesquisa. Tal fato se deveu ao interesse da instituição frente ao tema a ser abordado pela pesquisa.

A Instituição tem capacidade para 30 idosas e, à época da coleta dos dados contava com 28 senhoras institucionalizadas, com idades entre 60 e 93 anos. A equipe multidisciplinar responsável pelo cuidado dessas idosas era composta por: uma enfermeira, quatro técnicas de enfermagem, seis cuidadoras, um médico, uma assistente social e uma psicóloga. Os participantes da pesquisa foram informados sobre o vínculo institucional das pesquisadoras a uma universidade Federal de Minas Gerais e sobre o tema da pesquisa que propunham desenvolver na ILPI.

Os participantes do estudo foram idosas institucionalizadas e profissionais envolvidos no cuidado cotidiano. Foram critérios de inclusão para as idosas: ter idade igual ou superior a 60 anos, residir na Instituição há pelo menos três meses, ter fluência verbal que possibilitasse o diálogo e ter resultado do Mini Exame de Estado Mental com o escore de 20 para analfabetos, 25 para pessoas com um a quatro anos de escolaridade, 26,5 para aquelas com cinco a oito anos de escolaridade, 28 para indivíduos que estudaram de nove a 11 anos e 29 para aqueles com escolaridade superior a 11 anos $^{13}$. Os critérios de inclusão para os profissionais foram: ser profissional envolvido no cotidiano de cuidado das idosas, trabalhar na Instituição há pelo menos três meses, excluindo-se trabalhadores envolvidos exclusivamente com atividades administrativas e os de serviços gerais.

Para definição da amostra utilizou-se o critério de saturação dos dados, ou seja, a inclusão de participantes foi interrompida quando não mais levava à obtenção de novas informações ${ }^{14}$ sobre a constituição do discurso da autonomia das idosas institucionalizadas. Assim, a saturação foi alcançada com a participação de sete idosas e de 13 profissionais.

A idade das idosas participantes variou de 71 a 92 anos, com tempo de institucionalização de um a 13 anos. Quanto à escolaridade, três tinham ensino fundamental incompleto, uma o fundamental completo, duas tinham ensino médio e uma tinha ensino superior. Dos profissionais, 12 eram mulheres e um homem, com idade de 26 a 65 anos e tempo de trabalho na Instituição entre um e 30 anos. Cinco tinham formação de nível superior e oito de nível médio.

A equipe de pesquisa foi composta por uma pesquisadora com doutorado em Enfermagem, por uma aluna de mestrado em andamento, além de uma graduanda de Enfermagem inserida em programa de iniciação científica, a qual foi orientada e supervisionada, pelas enfermeiras, em todas as atividades das quais participou.

A coleta de dados se deu no período de janeiro a março de 2018, por meio de entrevistas de roteiro semiestruturado, com média de 15 minutos de duração, além de observação de campo. Em um primeiro momento, as entrevistas foram conduzidas pela pesquisadora mestranda, juntamente com a graduanda em enfermagem. Ambas foram treinadas pela pesquisadoradoutora em Enfermagem quanto à técnica de condução das entrevistas. 
O estabelecimento do rapport visa o acolhimento do pesquisado, para que o mesmo sinta confiança e favoreça sua participação na pesquisa ${ }^{15}$. A técnica foi aplicada pelas pesquisadoras ao abordar de forma respeitosa as idosas e os profissionais, em um ambiente reservado e acolhedor.

As idosas e os profissionais foram abordados para realização da entrevista durante as visitas à Instituição, sendo agendado dia e horário previamente. Houve a desistência de uma idosa em participar da pesquisa e a exclusão de uma profissional por trabalhar na Instituição há menos de três meses.

$\mathrm{O}$ roteiro de entrevistas das idosas continha as seguintes questões norteadoras: 1) Onde você vivia antes de vir para esta Instituição? 2) De quem foi a decisão de você vir morar aqui? Por quê? 3) Você se sente em condições de tomar decisões sobre as coisas que precisa fazer no dia-a-dia? Por quê?

No roteiro dos profissionais, as questões eram: 1) Como é, pra você, trabalhar em uma ILPI? 2) Como é seu cotidiano de trabalho na Instituição? 3) Você considera que os idosos dessa ILPI têm condições de tomar decisões sobre as coisas que precisam fazer em seu dia-a-dia? Por quê?

As entrevistas foram realizadas individualmente, em ambiente reservado na ILPI, com a presença das pesquisadoras e do entrevistado. Foram gravadas em equipamento Media Player e, posteriormente, transcritas pela enfermeira mestranda e pela aluna da graduação. Para a observação, foram feitas visitas de três a cinco vezes por semana durante o período da coleta de dados, com registro em diário de campo. O diário de campo era preenchido durante as entrevistas e concomitante à observação das pesquisadoras. A observação incluiu finais de semana, alternando-se os períodos da manhã, tarde e noite, até, aproximadamente, o horário de 20 horas.

Para fins de análise, todo o material coletado foi tratado como texto. A transcrição das entrevistas foi feita no Microsoft Word, convertendo-as em textos narrativos e as notas de campo conformaram textos de observação das práticas cotidianas da ILPI.

Os dados foram submetidos à análise de discurso (AD), que tem como o foco a linguagem e o seu uso $^{16}$, que foi usada neste estudo para explorar a constituição do discurso da autonomia das idosas. Os discursos são formados por elementos que não apresentam princípio de unidade, cabendo à $\mathrm{AD}$ buscar as regras que são capazes de reger sua formação, o que possibilita a determinação dos elementos que compõem o discurso ${ }^{17}$. A ênfase da AD é a análise do conhecimento interno da prática de uma determinada sociedade, o que se expressa por meio de sua linguagem, compreendendo-se que falas e textos são práticas sociais ${ }^{18}$.

$\mathrm{Na}$ constituição de seus discursos, os sujeitos elaboram um repertório de recursos discursivos com diferentes estratégias. Tais descrições não se resumem a meros relatos de uma cena, coisa ou pessoa, mas são orientados para a ação que as constituem e, portanto, contribuem para criar as realidades vividas pelas pessoas $^{16}$. As associações e análises feitas envolveram a interpretação dos textos constituídos a partir dos dados e seu significado implícito, com base no referencial pós-estruturalista ${ }^{19}$.

A primeira etapa da análise constituiu-se da leitura repetida e exaustiva dos textos produzidos a partir dos dados pelos pesquisadores envolvidos na investigação. A partir de então, discussões com a equipe de pesquisa permitiram a progressão e o desenvolvimento da análise dos dados, sendo identificadas e separadas estruturas discursivas de relevância dos textos, capazes de ampliar a compreensão da autonomia das idosas. Assim, procedeu-se a categorização dos elementos com características comuns, agrupando elementos, ideias ou expressões em torno de um conceito.

Apesar de serem encontrados diferentes temas na análise dos dados, o presente artigo aborda apenas a constituição do discurso da autonomia das idosas institucionalizadas. Logo após a coleta de dados, foi discutida com a gestora da ILPI à época e alguns participantes a importância dos resultados da pesquisa. Os resultados serão apresentados para os demais participantes e, dialogicamente, poderão possibilitar reflexões sobre a autonomia da pessoa idosa institucionalizada em ILPIs.

De acordo com os preceitos da Resolução $\mathrm{N}^{\circ}$ 466/2012, o projeto foi aprovado pelo Comitê de Ética 
e Pesquisa da Universidade Federal de Minas Gerais, sob Parecer n ${ }^{\circ} 2.470 .752 / 2018$. Foi mantido o sigilo das informações e a identidade dos participantes. Assim, os profissionais foram identificados, nos resultados da pesquisa, pela letra $\mathrm{P}$ e as idosas pela letra I e numerados de acordo com a sequência das entrevistas. Todos os participantes assinaram o Termo de Consentimento Livre Esclarecido.

\section{RESULTADOS}

A análise dos dados mostrou que, ainda que os profissionais relatem respeitar a vontade das idosas, as rotinas institucionais, de certa forma, definem e naturalizam os comportamentos das residentes na Instituição.

\begin{abstract}
"Se você colocar sentadinha vendo um programa, aí ela vai ficar. A não ser quando começar a incomodar, ou seja, uma coisa que não era do hábito mesmo ou que ela não tá gostando. Ela vai sinalizar e a gente vai retirar daquele ambiente. Mas a maioria segue a rotina institucional sem reclamar, sem ponderar, porque tá acostumada a ser dessa forma” (P4). “[...] tomo café antes de arrumar o quarto. Tomo café, arrumo o quarto, tomo banho [...]" (I2).
\end{abstract}

A ILPI se constitui em um local de rotinas, onde as atividades se repetem dia após dia. Diariamente, as idosas dependentes ficam agrupadas em determinados ambientes, como a sala de televisão ou a área próxima ao refeitório. Os horários nos ambientes comuns são predeterminados, estabelecendo-se, assim, o controle do uso dos espaços, o que cria um padrão de comportamento e permite estabelecer um melhor conhecimento sobre a localização das idosas:

\begin{abstract}
"Claro que, por ser uma instituição, tem as rotinas, não é?! Na casa, vocês podem perceber que a maioria das idosas não ficam no leito. A não ser que estejam com alguma indisposição, não é?!” (P12). "Olha, o meu dia a dia aqui é vinte e quatro horas na cama, porque eu tive trombose na perna direita [...] o meu dia a dia é na cama." (I5)
\end{abstract}

Os horários da maioria das atividades cotidianas são bem definidos. As idosas devem estar prontas para o café da manhã às 7h30min, de modo que os banhos se iniciam às 6 horas. Das 8 horas às 10 horas assistem televisão, às 11 horas é servido o almoço, à tarde assistem televisão de novo e, por fim, o jantar é servido às 17 horas. A rotina diária se encerra às 18 horas, quando as idosas, principalmente as dependentes são colocadas em suas camas para dormir.

A visita à instituição ocorreu entre janeiro e março, período de férias dos alunos que realizam atividades na casa. Dentre elas, estão as de fisioterapia, pesquisas de medicina, grupo de cantores e palhaços, aulas com um educador físico. Contudo, nesse período, a casa estava mais quieta e vazia, o que salietava a rotinização do dia a dia.

"Bom, aqui tem horário para tudo marcado! Tudo! [...] quando tá quase terminando a novela, eu já vou arrumando a cama pra dormir [...] quando bate para o jantar das moradoras às $5 \mathrm{~h}$, eu desço e pego ou sopa e leite pra tomar a noite" (I2).

Nesse contexto de rotinas tão bem estabelecidas, há pouco espaço para a tomada de decisão das idosas. Sua autonomia fica esquecida em rotinas que, de certa forma, deixam encobertos seus desejos, suas escolhas e sua própria liberdade, como aponta a profissional:

\footnotetext{
"É possível, um dia, um não querer determinada comida e comer outra comida? É possível sim! Então, enquanto isso não é um problema para a gente, a gente vai fazer. Vai ser problema o dia que várias... tiverem desejos diferentes. Aí, eu acho que homogeneíza mesmo, não tem jeito. Coletividade não dá pra pensar em cada um o tempo inteiro..." (P7).
}

O discurso da profissional aponta uma flexibilidade limitada da Instituição em relação aos desejos particulares das idosas, reconhecendo-se a supremacia da coletividade sobre a individualidade. No entanto, mesmo diante de um rol de regras e normas estabelecidas no cotidiano da ILPI, a obediência às mesmas nem sempre é percebida pelas idosas como uma forma de cerceamento de sua autonomia.

\footnotetext{
"Eu não gosto muito de sair, não. Mas se eu quero, eu decido que eu quero ir: "Irmã, eu estou querendo ir em tal a lugar assim, assim. Eu posso?” “Pode." E vou, entendeu!? Então, assim, a gente
} 
tem liberdade, sabe?” (I3). "[...] tem coisas que a gente tem que $[. .$.

falar com a coordenadora! O que você vai fazer e tal, não é?! Mas, por mim, a decisão, eu sei tomar. Mas, como eu moro aqui, então, a gente tem que obedecer, não é?! Dar satisfação" (I4).

O discurso mostra que o poder da norma e da regulamentação é exercido sobre elas, levando-as a se submeterem às regras estabelecidas. Ademais, as idosas têm suas vidas determinadas pelas normas institucionais de acordo com seu grau de dependência:

"Tem idosa que gosta de tomar banho 4 horas da manhã, 5 horas da manhã, mas tem idosa que quer tomar o banho mais ao longo do dia. Se ela for independente, não tem problema, mas se ela depender das cuidadoras, ela vai ter até 9 horas pra tomar o banho" (P12). "Em todo grupo social tem que ter as normas e limites. Então, aí, nós não podemos dar esse pleno direito de escolha, não é?! Então, algumas têm toda independência que quiser, não prendemos, nem nada. Mas outras, não têm. Então, é a minoria que tem sua independência e autonomia" (P11). "Eu acho ótimo sabe, porque, se eu tivesse assim dependente, eu acho que não ia ser tão boa assim, rs" (I3).

Observa-se, também, que a autonomia das idosas é colocada em xeque de acordo com limitações intelectuais e cognitivas que as impeçam de gerenciar suas próprias finanças e suas vidas:

"Elas não têm autonomia nenhuma. Elas são totalmente, assim, desprovidas de conhecimentos e são leigas. Muitas são analfabetas [...] Tem uma com deficiência mental. Já tem uma parte do intelectual delas... tão bem comprometidas. Elas não têm gerência. Não sabem, não dão conta de gerenciar a parte financeira." (P8).

No entanto, cabe considerar que, nem sempre, a submissão às normas se dá de forma passiva, suscitando expressão sutis de resistência às normas institucionais, certas tentativas de escapar ao controle estabelecido:

"[...] ela gosta muito de ficar ali na beirada do portão. Aí você vai na paciência: "fulana, vamos embora!” E ela: “Não!” Aí tem hora que, ou vai num arrancão mesmo "Vamos embora!" ou, se não, você tem que chegar e falar bravo mesmo "fulana vamos sair daí?!" (P2). "Então fica um pouco sofrido, que chega aqui, elas custam a adaptar, né?! Fica querendo ir embora, fica querendo fugir." (I3)

Os discursos mostram uma forma de resistência das idosas às normas institucionais. O desejo de fugir ou de ver as pessoas passeando nas ruas ou, ainda, a vontade de ver vida fora dos muros da Instituição faz com que ela fique próxima ao portão na expectativa de que surja uma oportunidade de fuga.

\section{DISCUSSÃO}

Autonomia é definida como um direito de tomar decisões, de pensar, de decidir e de agir, diante das próprias crenças e valores, baseando-se no que se acredita ser o melhor para $\mathrm{si}^{20}$. Nas instituições, de modo geral, é desafiador para a equipe promover a autonomia do idoso. O paternalismo profissional, quando o profissional passa a tomar decisões pelos idosos com o intuito de beneficiá-los, é uma das atitudes que pode comprometer a autonomia da pessoa institucionalizada ${ }^{21}$.

Um estudo realizado com enfermeiros sobre a percepção da autonomia do idoso na terminalidade da vida, mostrou que, para os profissionais, os idosos têm direito à autonomia, inclusive o poder de decisão sobre sua vida, entretanto, essa autonomia pode ser condicionada a determinados fatores, como doenças e nível de cognição para tomar decisões ${ }^{22}$. Além disso, os profissionais relacionam, de forma equivocada, a infância à velhice, desconsiderando toda a história de vida do idoso, como se eles não tivessem competência para geri-la ${ }^{21}$. Agindo assim, utilizam as normas e regras disciplinares da instituição como um meio de sobrepor suas verdades às dos idosos.

O poder disciplinar, no contexto institucional, age de forma silenciosa e sutil, adestrando os corpos para que eles se tornem dóceis ${ }^{17}$. Se por um lado a autonomia é exercida dentro de fronteiras espaciais, a disciplina é exercida sobre os corpos dos indivíduos, com poder de afetar os sujeitos capazes 
de ações voluntárias ${ }^{23}$. Na ILPI, por meio de relações hierarquizadas de poder, as normas são estabelecidas vislumbrando atender à coletividade para garantir a continuidade da dinâmica cotidiana de trabalho. Embora essas normas não sejam elaboradas com $\mathrm{o}$ intuito de restringir a autonomia individual das idosas, acabam por delinear seu limite de tomada de decisão. Assim, conforma-se um modelo de institucionalização que vem carregado de controle, disciplina, divisão e homogeneização ${ }^{23}$.

As inúmeras regras e rotinas homogeneízam a vida, em um cotidiano no qual impera a disciplinarização, com controle da vida das idosas e consequente diminuição de sua autonomia ${ }^{24}$. As idosas independentes ficam reclusas em seus quartos ou, com consentimento, podem sair da ILPI, enquanto as dependentes ficam nas salas de televisão, nos andares dos respectivos dormitórios. Apesar de as idosas independentes terem a possibilidade de escolha, elas acabam também se adequando às normas e sua autonomia fica esquecida no interior de cada quarto.

Homogeneizar o cotidiano das idosas torna menos complexa a organização das demandas para os cuidadores, reduzindo o espaço para a vontade e o querer. Nesse sentido, é importante considerar que condutas que realmente aumentam a autonomia dos sujeitos se baseiam em escolhas significativas para eles, o que envolve questionar o outro sobre questões triviais e prestar atenção em pequenos detalhes ${ }^{24}$.

Em um estudo realizado no México com mais de mil idosos, com o objetivo de avaliar a percepção dos próprios idosos sobre a sua autonomia, identificou-se que mesmo idosos com comprometimento cognitivo podem responder coerentemente a perguntas sobre preferências, escolhas e sua participação nas decisões sobre a vida diária, fornecendo informações precisas e confiáveis. Os resultados indicaram também que o comprometimento cognitivo está associado a baixa percepção de autonomia, que pode levar a altos níveis de ansiedade, depressão e a perda da independência ${ }^{25}$.
Durante a coleta de dados da pesquisa, o regimento da ILPI se encontrava em fase final de elaboração pela coordenação, juntamente com a equipe de cuidados. No entanto, mesmo não havendo, naquele momento, uma regulamentação formal das normas institucionais, as regras e rotinas estavam implicitamente colocadas, sendo de conhecimento tanto das residentes quanto dos profissionais.

Por outro lado, percebe-se que, na perspectiva dos profissionais, nem sempre a autonomia das idosas é reconhecida, devido ao fato de as mesmas não terem mais gerência e conhecimento. $\mathrm{O}$ poder produz saber e vice-versa, estando o binômio poder/ saber diretamente relacionado, de modo que não há relação de poder sem a paralela de um campo de saber, nem saber que não constitua relações de poder $^{23}$. O poder da equipe sobre a vida cotidiana das idosas estava incorporado na organização, sendo institucionalizado nas estruturas predominantes e constantemente recapturado ${ }^{26}$.

Por fim, cabe salientar que para todo exercício do poder, existe, em contrapartida, o custo a ser pago por ele, ou seja, uma resistência ao poder instituído. $\mathrm{O}$ espaço institucional, por suas inúmeras regras, rotinas, relações hierarquizadas, com consequente restrição da autonomia, provoca expressões de resistência representadas por insatisfação, discordância e invenção de espaços próprios e imaginários. Nesse contexto, o sujeito encontra suas possibilidades de subjetivação e constrói estratégias de resistência ou subversão às ordens sociais que o limitam, que são representadas por atos de liberdade ${ }^{27}$. As estratégias de resistência das idosas ocorrem nos momentos de fuga, o que fez a instituição instalar portões e câmeras por toda parte.

Dentre as limitações da pesquisa destaca-se o fato de a mesma ter sido realizada em apenas uma ILPI. Entretanto, espera-se que este estudo possa contribuir para a reflexão de uma velhice digna, pois os idosos continuam sendo segregados e excluídos do convívio com a sociedade. Mantem-se a logica asilar, ao invés de inserí-los na comunidade e tornálos ativos e autônomos. 
Assim, ressalta-se a importância e a necessidade de novos estudos que ampliem o olhar sobre a autonomia de idosos institucionalizados e que abranjam a perspectiva de grupos mais heterogêneos.

\section{CONCLUSÃO}

Os resultados da pesquisa apontam que, para um funcionamento adequado da estrutura composta por pessoas diferentes que residem e trabalham nesse ambiente, limites e regras são necessários. Entretanto, apesar da ILPI ser uma instituição regida por normas, é importante considerar que as normas não são utilizadas, primariamente, como instrumento de controle e cerceamento do exercício de tomada de decisão das idosas.

A transição epidemiológica tem acelerado a transformação da relação da sociedade com as ILPIs, bem como tem exigido dessas instituições mudanças em suas práticas cotidianas. A ideologia, a estrutura física e a organização do ambiente de uma ILPI, bem como a prática profissional, funcionam como

\section{REFERÊNCIAS}

1. Veras RP, Oliveira M. Envelhecer no Brasil: a construção de um modelo de cuidado. Ciênc Saúde Colet. 2018;23(6):1929-36. Disponível em: https://doi. org/10.1590/1413-81232018236.04722018 .

2. Figueiredo MCCM, Ferreira FA, Nunes ESC, Araújo AM, Araújo PE, Souza GP, et al. Idosos institucionalizados: decisão e consequências nas relações familiares. Rev Kairós. 2018;21(2):241-52. Disponível em: http://dx.doi.org/10.23925/2176901X.2018v21i2p241-252 .

3. Blais S, McCleary L, Garcia L, Robitaille A. Examining the benefits of intergenerational volunteering in Long-Term Care: a review of the literature. J Intergenerat Relat. 2017;15(3):258-72. Disponível em: https://doi.org/10.1080/15350770.20 17.1330056

4. Goffman E. Manicômios, prisões e conventos. $9^{\mathrm{a}}$ ed. São Paulo: Perspectiva; 2019

5. Natalino MAC. Isolamento, disciplina e destino social em comunidades terapêuticas. In: Santos MPG. Comunidades terapêuticas: temas para reflexão. Rio de Janeiro: IPEA; 2018. p.. 37-60. uma trama que reforça a dependência e minam a autonomia da pessoa idosa, emergindo dos discursos de profissionais e idosas.

No entanto, é preciso que se avance mais no tocante às políticas públicas específicas para as ILPIs, com a definição clara de seu papel e diretrizes para uma prática qualificada. Também merece atenção do poder público o financiamento das ILPIs, a fim de que seja possível viabilizar seu adequado funcionamento, estrutura física capaz de atender às demandas da pessoa idosa, bem como prover corpo profissional devidamente qualificado.

Ainda é limitado o conhecimento sobre essas práticas e seus efeitos na vida dos idosos que vivem a realidade da institucionalização, inclusive no que se refere à sua autonomia. Assim, espera-se que este estudo possa contribuir para reflexões acerca de questões que envolvem a manutenção e ampliação da autonomia do idoso no cotidiano institucional.

Editado por: Marquiony Marques dos Santos

6. Miranda GMD, Mendes ACG, Silva ALA. Population aging in Brazil: current and future social challenges and consequences. Rev Bras Geriatr Gerontol. 2016;19(3):507-19. Disponível em: https://doi. org/10.1590/1809-98232016019.150140 .

7. Motloba PD. Understanding the principles of autonomy. South Am Dent J. 2018;73(6):418-20.

8. Castoriadis C. A instituição imaginária da sociedade. Rio de Janeiro: Paz e Terra; 2007.

9. Deon RG, Goldim JR. Capacidade para tomada de decisão em idosos institucionalizados e não institucionalizados. Estud Interdiscipl Envelhec. 2016;21(1):123-33. Disponível em: https://seer.ufrgs. br/RevEnvelhecer/article/view/54047/40716 .

10. Minayo MCS. Amostragem e saturação em pesquisa qualitativa: consensos e controvérsias. Rev Pesqui Qual. 2017;5(7):1-12. Disponível em: https:// edisciplinas.usp.br/pluginfile.php/4111455/mod_ resource/content/1/Mina yosaturacao.pdf. 
11. Velloso ISC, Araújo MT, Alves M. Práticas de poder no serviço de atendimento móvel de urgência de Belo Horizonte. Rev Gaúcha Enferm. 2012;33(4):126-32. Disponível em: https://doi.org/10.1590/S198314472012000400016.

12. Dreyfus HL, Rabinow P. Michel Foucault: uma trajetória filosófica. $2^{\mathrm{a}}$ ed. Rio de Janeiro: Forense Universitária; 2010.

13. Brucki SMD, Nitrini R, Caramelli P, Bertolucci PHF, Okamoto IH. Suggestions for utilization of the mini-mental state examination in Brazil. Arq Neuropsiquiatr. 2003;61(3B):777-81. Disponível em: https://doi.org/10.1590/S0004-282X2003000500014.

14. Saunders B, Sim J, Kingstone T, Baker S, Waterfield J, Bartlam B, et al. Saturation in qualitative research: exploring its conceptualization and operationalization. Qual Quant. 2018;52(4):1893-907.

15. Freitas ICF, Silva CN, Adan LFF, Kitaoka EG, Paolilo RB, Vieira LA, et al. Pesquisa qualitativa em saúde: um olhar inovador sobre a produção do conhecimento científico. Rev Baiana Saúde Pública. 2011;35(4):1001-12. Disponível em: https://doi. org/10.22278/2318-2660.2011.v35.n4.a270.

16. Gyberg A, Henoch I, Lepp M, Wijk H, Ulin K. Written reports of adverse events in acute care: a discourse analysis. Nurs Inq. 2019;26:e12298.

17. Foucault M. Vigiar e punir: nascimento da prisão. Petrópolis: Vozes; 2014.

18. Hassen R. Discourse as medium of knowledge: transmission of knowledge by transmission of discourse people live. 2015;6(31):119-28. Disponível em: https://files.eric.ed.gov/fulltext/EJ1083383.pdf .

19. Mula JM, Estrada JG, Campaner CP. Impact of interprofessional relationships from nurses' perspective on the decision-making capacity of patients in a clinical setting. Int J Environ Res Public Health. 2018;15(1):1-10.
20. Campos A, Oliveira DR. A relação entre o princípio da autonomia e o princípio da beneficência. Rev Bras Est Políticos. 2017;115:13-45. Disponível em: http:// doi.org/10.9732/P.0034-7191.2017V115P13 .

21. Santos RAAS, Corrêa RGCF, Rolim ILTP, Coutinho NPS. Atenção no cuidado ao idoso: infantilização e desrespeito à autonomia na assistência de enfermagem. Rev Pesqui Saúde. 2016;17(3):179-83. Disponível em: http://www.periodicoseletronicos. ufma.br/index.php/revistahuufma/article/view/6793

22. Gaspar RB, Silva MM, Zepeda KG, Silva IR. O enfermeiro na defesa da autonomia do idoso na terminalidade da vida. Rev Bras Enferm. 2019;72(6):1639-45. Disponível em: https://doi. org/10.1590/0034-7167-2018-0768

23. Raj PPE. Foucault and spatial representation. PILC J Dravidic Stud. 2019;3(1):57-76. Disponível em: https://www.academia.edu/40414443/Foucault_and_ Spatial_Representation .

24. Andrews GJ, Holmes D, Poland B, Lehoux P, Miller KL, Pringle D, et al. 'Airplanes are flying nursing homes': geographies in the concepts and locales of gerontological nursing practice. J Clin Nurs. 2005;14(8b):109-20.

25. Sánchez GS, García PC, Ramírez GE, Moreno TK, Cantú QGR. Decreased autonomy in community-dwelling older adults. Clin Interv Aging. 2019;14:2041-53. Disponível em: https://doi. org/10.2147/CIA.S225479 .

26. Wikström E, Emilsson UM. Autonomy and control in everyday life in care of older people in nursing homes. J Housing Elder. 2014;28(1):41-62.

27. Tucci A. Political subjectivations: between freedom and dependency. Política Comun. 2016;9(1):1-7. 